\title{
The Application of Multi - teaching Mode in the Course Reform of Communication

\author{
Hai-Yi ZHANG ${ }^{\mathrm{a}}$ and Yong SONG ${ }^{\mathrm{b}^{*}}$
} \\ College of Electrical and Information Engineering, Beihua University, Jilin, China \\ a44167501@qq.com, b1752315651@qq.com \\ ${ }^{*}$ Corresponding author: Yong SONG
}

Keywords: Multi-teaching mode; microlecture; virtual experiment platform; matlab

\begin{abstract}
Communication theory is a strong theoretical basic course with rich content. To enable students to better learn the important lessons, multi-dimensional teaching model teaching reform is adopted. Application of new multimedia courseware in the classroom teaching is a more intuitive way to explain. Outside the classroom in the form of micro-lessons provide students with more convenient conditions for learning; stimulate students' interest in learning. On the experimental teaching MATLAB software and virtual experiment platform is used to improve the lack of hardware laboratory equipment. Practice has proved that the use of multi-dimensional teaching model teaching effect has been significantly improved.
\end{abstract}

\section{Introduction}

Communication principle course is a professional basic course of communication, information, and electronics and so on. Students learn communication theory courses to comprehend the communication system, master communication system of the basic theories and methods of analysis, so that students in further learning process and have a good theoretical basis and ability to work in the future. However, the communication principle course is strong theoretical, therefore, difficult for teachers to teach and students to learn has been primary puzzles of this course [1].Since the year 2014,the group proposed and applied multi-teaching mode in communication theory curriculum reform,the model is shown in Fig.1.Through the implementation of the reform program, to guide students to understand and master the knowledge of the principles of communication content and apply their knowledge, and achieved good teaching results from a practical point of view, to foster a solid theoretical foundation, practical ability and innovative synthetic quality talents lay a good foundation.

\section{Teaching Reform}

Communication principles Course content abstraction, professional terminology, mathematical derivation of the formula, in order to learn this course on the students' higher mathematics requirements but also on the professional knowledge has a strong ability to understand.

So that the form of writing on the blackboard to explain now completely unable to meet the teaching requirements, and multimedia teaching methods in recent years has been adopted by more colleges and universities are mostly just stay in a simple to use software PPT form, the original writing on the blackboard in the form of an easy migration to the multimedia slide show, so no improvement in the teaching form and nature, but also the advanced nature of multimedia courseware not reflected, a direct consequence of this result is that students sleeping in class more, play more games, read the novel more, less really understand, and therefore improve the quality of teaching is difficult to obtain.

To change this situation, change the original group plus PPT kind of writing on the blackboard mode, developed with diverse forms of new courseware with Flash animation, streaming media and 
other forms of basic concepts in courseware, formulas, and other abstract theoretical derivation of theoretical formulas visualize[2].

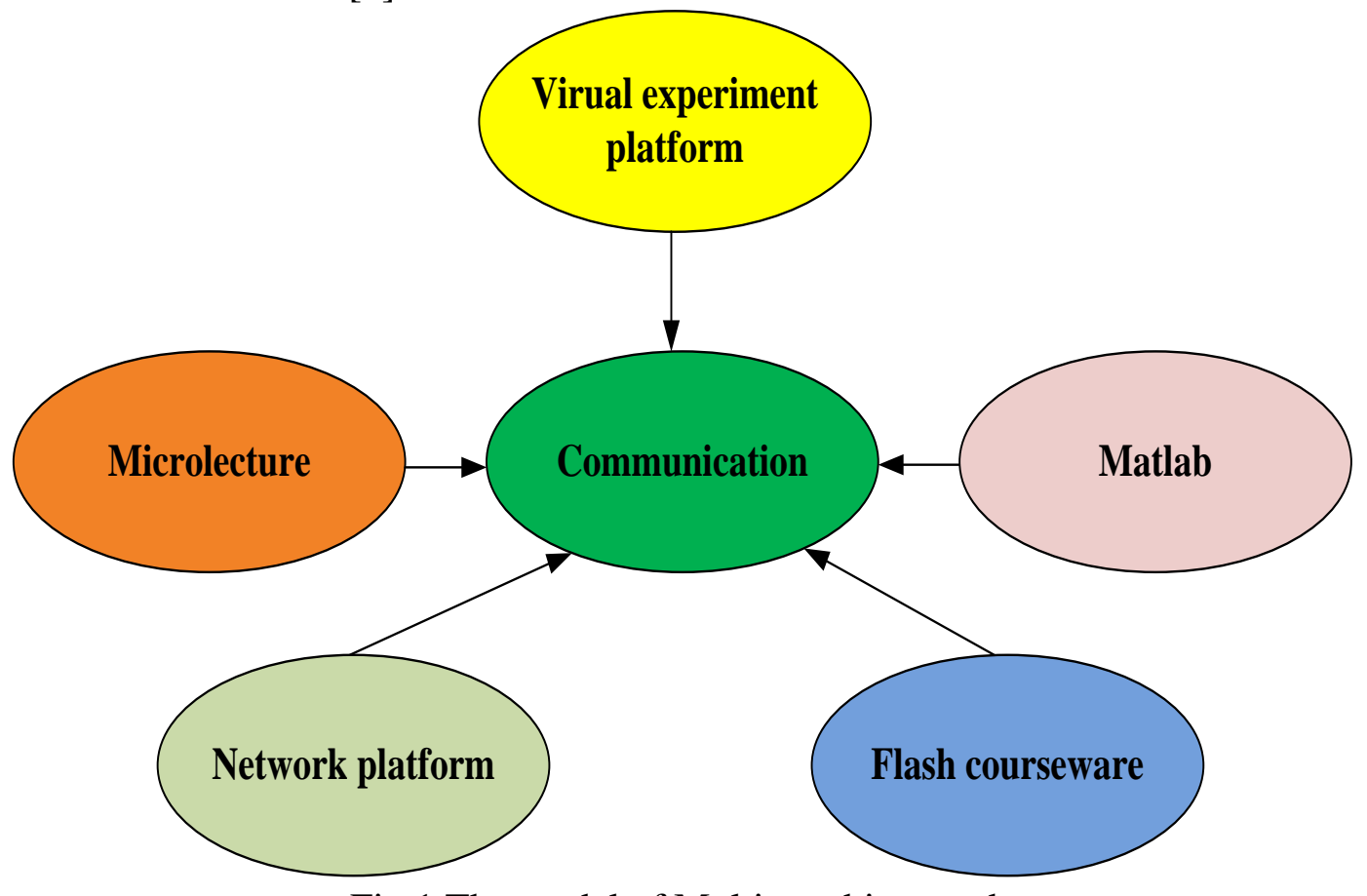

Fig.1 The model of Multi-teaching mode

For example, when explaining the Nyquist sampling theorem, adding video and audio playback in case of courseware. By playing the audio and video sampling results from different samples of students vivid and intuitive understanding of the sampling theorem, give full play to the advanced nature of the media, edutainment, the boring theoretical knowledge with vivid way presented, both to improve students' interest in learning professional knowledge, but also reduce the difficulty of understanding the knowledge itself, so boring theory is no longer boring.

Through this case teaching, the theory with practice, not only active classroom atmosphere also increased student interest in learning, to deepen students' understanding of the problem, the students re-"back" to the classroom, the effective use of classroom time.

\section{Selection of teaching materials}

Teaching materials are indispensable tools for students to learn. At present, the common phenomenon of communication theory teaching materials is the emphasis on the theoretical knowledge of the development of the latest developments in the field of communications and the latest technology, especially the application of new technology background and application effects introduced. From the development of modern communications industry point of view, the West is indeed ahead of China.

Foreign textbooks on the new technology, new results are more closely track [3]. Therefore, the group adopts the original English textbooks, the classroom mainly bilingual teaching mode, so that students master the basic principles of communication at the same time, can understand the development of new technologies, enrich students' professional knowledge, and promote students to improve their English proficiency and the ability to access the relevant English literature, and thus promote the professional learning teaching effect.

\section{MicroLecture}

Since 1960s, teachers in schools in the United States and other countries began to develop"Mini course" (Mini-course, Mini-Lesson, or Micro-curriculum),Focused on the design and implementation of a small scale short course[4].In the autumn of 2008, the senior teaching design of 
San Juan College of New MexicoTeacher, College Online Service Manager David Penrose put forward"Micro Courses" concept, pioneered the famous "one minute micro video"The core idea of the "micro curriculum" (Microlecture) is to put the teachingcontent and teaching objectives are closely linked, in order to produce a more focused learning experience".David Penrose has thus been dubbed the "one minute professor", he called the micro course"Burst Knowledge ".China first proposed the concept of micro course Guangdong Foshan Education Bureau Hu Tiesheng [5] believes that micro course refers to the standard and in accordance with the requirements of the new curriculum teaching practice, the teaching video as the main carrier, reflect the organic combination of various teaching resources, teachers in the classroom teaching process for a knowledge point or teaching and carry out teaching and learning activities."[6]

In the current class communication theory courses continue to be compressed under the premise of traditional classroom learning has completely failed to meet the education needs of communication theory in this course, then how to use the students' spare time to complete the communication principle of learning isa problem. In order to solve the problem and improve the ability of students to use their spare time for self-study, the research group proposed model micro Course.

Based on teaching design, the use of multimedia technology in more than five minutes on a point of knowledge there is a targeted audio or video explain. In education, the micro-lesson taught content was "dot" shape, fragmentation, knowledge of these points can be textbook interpretation questions succinctly, summed up the test center; it can be a method to impart knowledge of teaching experience and other skills explain and demonstrate.

Communication principle has a lot of knowledge. The difficulty of the existence of various knowledge points and the degree of focus is different. The knowledge points will be dispersed to record different lengths of video, the video and audio uploaded to the network platform, students can log on the network through the mobile terminal platform to click on the content of interest to achieve the autonomy of learning time, place and content.

\section{Experimental teaching methods combining software and hardware}

In communication theory course, practical aspects of the experiment is essential, by experiment allows students to better understand what you have learned, to improve students' ability and analytical skills to solve practical problems.

In the traditional hardware experiment, the integrated experimental system is a comprehensive experimental system of communication principle produced by Tianhuang Instrumentcorporation

The main features of the experimental box is a modular design, each module using an independent power switch, can be self-configured as required. Including the communication system source coding technology, teaching content baseband and bandpass transmission technology, digital modulation and demodulation techniques, multiplexing, synchronization and interface technology, communication theory courses. But with the increase of life, laboratory equipment, teaching will gradually wear and tear of aging, the probability of error when making partial validation experiments will increase and may reach over the principle of verification results.

The group also introduces Matlab simulation into experimental teaching.

Students can design their own programs according to the content, the preparation of procedures for the simulation of knowledge points. Through this process, many abstract esoteric theories become vivid, concrete, students can better understand the formula to express the meaning, from the graphics to further deepen the understanding of knowledge and master. From the rote memorization formula into the understanding of the formula and graphics-based, to reduce students in the learning process of the difficulties, so as to effectively improve the enthusiasm and interest in learning, develop independent innovation ability, improve the ability to analyze and solve problems and integrated design ability. 


\section{Virtual Experiment Platform}

Due to restricted opening hours and other school laboratory and site factors in the after-school students who want to continue to study the course content and practice is unrealistic [7]. Therefore, in order to improve students' hands-on requirement, the research team used a virtual experiment platform which is shown in Fig.2.

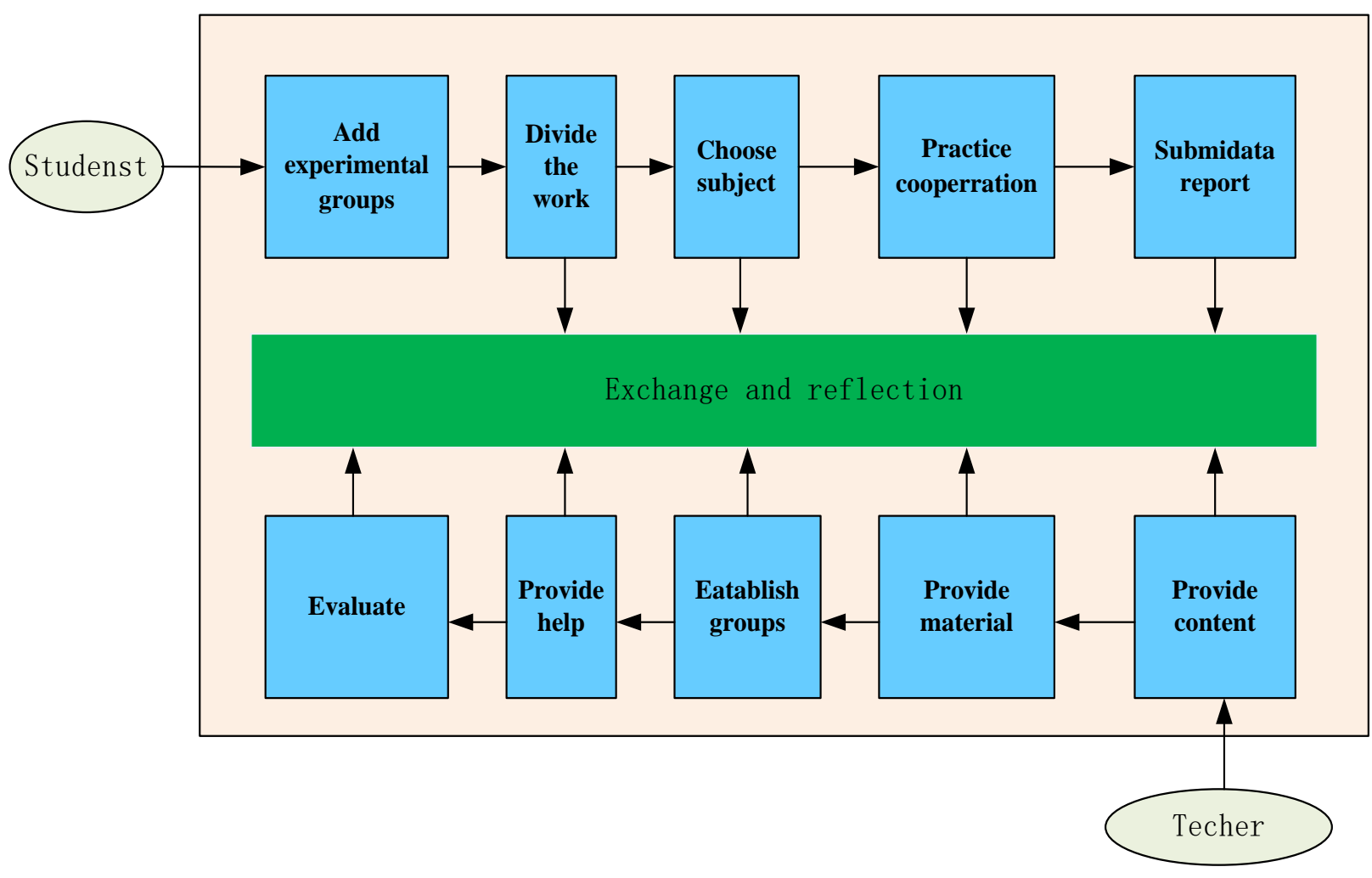

Fig.2. virtual experiment platform

Virtual experiment system unrestricted time and place, as long as there is a computer and Internet, students can begin to configure, connect, adjust and use of laboratory equipment to complete the necessary experiments through virtual experimentation platform themselves, students entering after experimental platform, free to choose the pilot project to be completed, familiarize yourself with the experimental task and select single or multiplayer cooperative complete. During the experiment, students can feel free to communicate with other students or teachers, there is a problem in the experiment by the experimenter chooses to watch experimental demonstrations, or to ask teachers or classmates to solve the problem.

Students in this manner multilateral collaboration to complete the test and submit test reports. The system will automatically record the test results and records of students, and the data is fed back to the teacher. After the completion of the experiment, students can enter the virtual experiment forum, with the teacher or other students in the experimental analysis of the problems together, exchange and reflection. This experimental environment promotes the enthusiasm of students and fosters students' innovative ability.

\section{Conclusions}

In multi- teaching mode, communication theory course by updating teaching content, improve the theory and practice of teaching methods, and other reform measures to continuously improve the quality of teaching and teaching effectiveness, through years of reform practice, the quality of my students courses on communication theory evaluation has gradually increased in the college students' employment rate has been among the best, at the same time, the number of graduate 
students admitted to this increasing year by year. These results show clearly that curriculum reform has been noticed.

\section{Acknowledgement}

This research was financially supported by 2014Beihua University Youth Teaching Research Project, Jilin, China .

\section{References}

[1] Chen Fangni. Discussion on the reform of communication principle course for application oriented personnel training (J). Journal of Zhejiang University of Science and Technology, 2014,26 (1): 68-71.

[2] Shen Wenli, Yu Yanping, Jia Bo. Classroom and experimental teaching reform of communication theory (J). Experimental science and technology, 2014,12 (1): 55-57.

[3] Zeng Wenjie. Miniature: research, development of [J]. Education of school-based curriculum development in 2009 (4): 51-55.

[4] Guan zhong guest. Micro curriculum [J]. China information technology education, 2011, (17): 14-15.

[5] Hu Tiesheng. "Micro class": [J]. audio-visual education a new trend in the development of regional educational information resources 2011, (10): 61-65.

[6] China Microlecture[OL].<http://www.cnweike.cn.>.

[7] Yu Xiaojie, Zhou Cunshan, Fu celebration, etc. open virtual experiment platform construction and management mode of [J]. Anhui Agricultural Science Bulletin, 2011,17 (22): 119-120. 